\title{
Interleukin 12 is a primary cytokine responding to influenza virus infection in the respiratory tract of mice
}

\author{
Y. HAMA ${ }^{1}$, M. KUROKAWA ${ }^{2}$, M. IMAKITA ${ }^{3}$, Y. YOSHIDA ${ }^{1}$, T. SHIMIZU², W. WATANABE ${ }^{2}$, K. SHIRAKI $^{*}$ \\ ${ }^{1}$ Department of Virology, University of Toyama, 2630 Sugitani, Toyama 930-0194, Japan; ${ }^{2}$ Department of Biochemistry, School \\ of Pharmaceutical Sciences, Kyushu University of Health and Welfare, Yoshino 1714-1 Nobeoka, Miyazaki 882-8508, Japan; \\ ${ }^{3}$ Department of Pathology, Rinku General Medical Center, Izumisano, Osaka 598-0048, Japan
}

\begin{abstract}
Summary. - We have reported previously that an increase in interleukin 12 (IL-12) production in the lungs of mice infected with Influenza A virus or an intranasal (i.n.) administration of IL-12 to the infected mice alleviated pneumonia (Tsurita et al., J. Pharmacol. Exp. Therapeut. 298, 362-368, 2001). In this study, we found that in the bronchoalveolar lavage fluids (BALF) obtained from mice infected i.n. with Influenza A virus IL-12 was elevated on day 1 post infection (p.i.) and was followed by tumor necrosis factor $\alpha$ (TNF- $\alpha$ ), IL-18, and interferons $\alpha, \beta$, and $\gamma$ (IFN- $\alpha,-\beta$, and $-\gamma$ ) on day 2 p.i. Histochemical analyses of the infected lungs on day 1 p.i. showed the presence of IL-12 and IL-12 mRNA in mononuclear and macrophage-like cells and colocalization of macrophages with viral antigen, while other cytokines were absent. Thus, IL-12 was produced by macrophages infiltrating the infected epithelium as the first response cytokine and its production at the site of infection may direct an early immune defense to alleviate the severity of infection.
\end{abstract}

Keywords: Influenza A virus; interleukin 12; cytokines; macrophages; mice; pneumonia

\section{Introduction}

In the influenza infection cytokines are produced locally and systemically and their production is important in promoting host-immune defense to alleviate symptoms especially in the early stage of infection (Hayden et al., 1998; Kaiser et al., 2001; Cheung et al., 2002; Seo et al., 2002; Van Reeth, 2002). In a murine model, cytokines such as IL-12 and IL-18 as Th1 immune-response mediators, IFN- $\gamma$ as a Th1 cytokine, IL- 4 and IL-10 as Th2 cytokines, IL- $1 \alpha$, IL-1 $\beta$, IL-6, and TNF- $\alpha$ as inflammatory cytokines, and IFN- $\alpha,-\beta$ have been shown to be produced in the respiratory tract during infection (Hennet et al., 1992; Kurokawa et al., 1996a,b, 2002; Tsurita et al., 2001; Liu et al., 2004).

"Corresponding author. E-mail: kshiraki@med.u-toyama.ac.jp; fax: $+8176-4345020$.

Abbreviations: $\mathrm{BALF}=$ bronchoalveolar lavage fluid; IFN $=$ interferon; $\mathrm{IL}=$ interleukin; i.n. = intranasal; $\mathrm{MAb}(\mathrm{s})=$ monoclonal antibody(ies); p.i. = post infection; $\mathrm{TNF}=$ tumor necrosis factor
The timely augmentation of IL-12 and IFN- $\gamma$ levels in the airways of mice has been shown to alleviate pneumonia in the early phase of influenza infection (Tsurita et al., 2001; Kurokawa et al., 2002). IL-12 is a strong inducer of IFN- $\gamma$ and is important in the development of Th1 cells followed by the generation of cell-mediated immunity contributing to the elimination of influenza virus (Monteiro et al., 1998). IL-18, a novel cytokine with potent IFN- $\gamma$-inducing activity, plays an important role in NK cell activity and the Th1-mediated immune response in collaboration with IL-12 (Kaiser et al., 2001; Tsurita et al., 2001; NeffLaFord et al., 2003; Liu et al., 2004). Kaiser et al. (2001) reported that the magnitude of the early decrease in viral titers correlated with initial levels of IFN- $\gamma$ in nasopharyngeal lavage fluid of human volunteers. IFN- $\gamma$ is suggested to be the critical cytokine in the cytokine cascade due to the influenza infection as well as to be responsible for viral clearance in humans. TNF- $\alpha$, IFN- $\alpha$, and IFN- $\beta$ are also known to be produced locally in the early phase of influenza infection. Like IFN- $\gamma$ they were reported to 
have potent antiviral properties for the influenza virus and responsibility for the pathogenesis of influenza infection through reduction of virus yield (Cheung et al., 2002; Seo and Webster, 2002; Neff-LaFord et al., 2003; Szretter et al., 2007). Thus, IL-12, IL-18, TNF- $\alpha$, and IFN- $\alpha,-\beta,-\gamma$ are produced in the early phase of influenza infection and may direct early host immunity against the influenza infection. However, an order which they are produced after influenza infection and how they contribute to early host-immune defense against influenza infection is unclear.

In this study, we pursued the production kinetics of IL-12, IL-18, TNF- $\alpha$, and IFN- $\alpha,-\beta,-\gamma$ and viral antigen in BALF from the lungs of Influenza A virus-infected mice using ELISA, hybridization in situ, and immunohistochemical methods. We found that the production of IL-12 preceded that of other cytokines. Thus, the primacy of IL-12 production in the cytokine cascade was confirmed and as a result, it was suggested that IL-12 directed the early host immune defense against Influenza A virus infection.

\section{Materials and Methods}

Virus and cells. A mouse-adapted Influenza virus [A/PR/8/34 (H1N1)] was propagated in the lungs of mice and stored as described previously (Kurokawa et al., 1996a,b, 1998, 2002; Furuta et al., 2002). MDCK cells were grown and maintained in MEM supplemented with $5 \%$ or $2 \%$ heat-inactivated calf serum.

Mice. Female DBA/2 Cr mice (7-week-old, 19-21 g) were purchased from Japan SLC Inc. The mice were housed by 5 animals/cage in specific-pathogen-free conditions under a $12 \mathrm{hrs}$ light/dark cycle. The temperature in the room was kept at $23 \pm 2{ }^{\circ} \mathrm{C}$. The experimental protocols were approved by the Animal Experiment Committee of University of Toyama and Kyushu University of Health and Welfare, Japan, and their animal experimentation guidelines were followed in the animal studies.

Mice were infected i.n. with $10^{3} \mathrm{PFU} / 25 \mu \mathrm{l}$ of influenza virus or mock-infected with PBS under anesthesia (Kurokawa et al., 1996b, 2002). The body weight of infected mice was measured daily.

$B A L F$ preparation. BALF was prepared from 4 to 6 mice on days 1 to 4 p.i. and the supernatant after centrifugation was stored at $-80^{\circ} \mathrm{C}$ (Kurokawa et al., 1996a,b, 1998, 2002).

Virus titration. Virus titers in BALF from influenza virusinfected mice were examined on days 1 to 4 p.i. Virus titers of the stored supernatant of BALF were determined by the plaque assay as described previously (Kurokawa et al., 1996a,b, 2002).

ELISA of cytokines. The levels of cytokines were examined in BALF on days 1 to 4 p.i. IL-12, IL-18, IFN- $\gamma$, and IFN- $\alpha,-\beta$ levels in BALF were determined using ELISA kits (Amersham, Medical \& Biological Laboratories, BioSource International, PBL Biomedical Laboratories, respectively) according to the manufacturers' instructions. The level of IL-12 was measured as the level of IL-12 p70 that was biologically active.

Immunohistochemical analyses. The lungs of infected mice were removed under anesthesia from at least 3 mice in each group on days 1 and 2 p.i. and fixed for hematoxylin and eosin staining or rapidly frozen in liquid nitrogen for immunohistochemical examination as described previously (Imakita et al., 2000; Kamiyama et al., 2001; Fukuda et al., 2003). Briefly, $6 \mu \mathrm{m}$ thick serial sections of the frozen lungs were dried at room temperature, fixed with cold acetone, and then washed with TBS. Endogenous peroxidase, biotin, and alkaline phosphatase were blocked by treatment with $0.3 \% \mathrm{H}_{2} \mathrm{O}_{2}$ in methanol, Biotin Blocking System or Levamisole (both Dako), respectively. After blocking with blocking solution (10\% rabbit or goat normal serum, 2\% BSA, $0.1 \%$ Triton-X 100 in TBS), the sections were incubated with the primary antibodies; rat anti-mouse MAbs to IL-12 (p40/70) (1:25, BD Bioscience Pharmingen), IFN- $\gamma$ (1:25, BD Bioscience Pharmingen), F4/80 antigen of mature tissue macrophages (1:200, Serotec), and IL-18 (1:50, MBL), and MAb to influenza nucleoprotein (NP) (1:15, Fujita Health University). The sections treated with antibodies to IL-12, IFN- $\gamma$, IL-18, or F4/80 antigen were incubated with biotinylated rabbit anti-rat $\operatorname{IgG}$ (Dako), developed in streptoavidin/alkaline phosphatase or a horseradish peroxidase complex (Dako) with the BCIP/NBT or DAB substrate-chromogen system (Dako), and counterstained with nuclear fast red or Mayer's hematoxylin. The sections with antibody to influenza NP were incubated with peroxidase-conjugated goat anti-rat IgG (Jackson ImmunoResearch Lab) at room temperature for $1 \mathrm{hr}$, and the DAB substrate-chromogen system (Dako) was used for visualization of the immune reaction.

In situ hybridization was performed to detect IL-12 mRNA using the digoxigenin-labeled murine IL-12 p40 DNA probe. Mice were perfused with $0.1 \mathrm{mo} / 1$ phosphate buffer $(\mathrm{pH} 7.4$ ) containing $4 \%$ paraformaldehyde and the lungs were rapidly frozen in liquid nitrogen as described by Kamiyama et al. (2001). Briefly, the frozen sections ( $6 \mu \mathrm{m}$ thick) were fixed with $4 \%$ paraformaldehyde in PBS and were treated with $0.2 \%$ Triton-X 100 and $10 \mu \mathrm{g} / \mathrm{ml}$ proteinase $\mathrm{K}$. They were again fixed with $4 \%$ paraformaldehyde and immersed in $2 \mathrm{mg} / \mathrm{ml}$ glycine sequentially dehydrated with ethanol and dried. The IL-12 probe was prepared from total RNA of murine spleen by reverse PCR (Kurokawa et al., 2003). The digoxigenin-labeled murine IL-12 p40 DNA probe was generated as a 497-bp fragment by PCR using a DIG DNA Labeling Mix (Roche) with the forward primer 5'-TCTCTGTCTGCAGAGAAGGTCACACTGGAC-3' and reverse primer 5'-CTAGGATCGGACCCTGCAGGGAACA ATGC-3'. The sections were pre-hybridized with $50 \%$ formamide in $5 x$ SSC and then hybridized with denatured digoxigenin-labeled probes at $46^{\circ} \mathrm{C}$ overnight (Kamiyama et al., 2001; Fukuda et al., 2003). To detect bound digoxigenin-labeled probes, the sections were blocked with blocking solution [1\% blocking buffer (Roche Applied Science), 0.1\% Triton-X 100 in $0.1 \mathrm{~mol} / \mathrm{l}$ Tris-HCl, 0.15 $\mathrm{mol} / \mathrm{l} \mathrm{NaCl}(\mathrm{pH} 7.5)]$ at room temperature for 30 mins. They were incubated for $2 \mathrm{hrs}$ with alkaline phosphatase-coupled anti-digoxigenin antibody (Roche). After washing $3 \mathrm{x}$ with TBS, the reaction was developed with BCIP/NBT (Dako). Hybridization without DIG-labeled probes and with RNase-treated sections was used to confirm the absence of positively-stained IL-12 mRNA.

Statistical analysis. Student's $t$-test was used to evaluate the significance of the differences in mean cytokine levels on the days examined. $\mathrm{P}<0.05$ indicated statistical significance. 


\section{Results}

\section{Levels of cytokines in BALF from virus-infected mice}

The kinetics of IL-12, IL-18, TNF- $\alpha$, and IFN- $\alpha,-\beta,-\gamma$ production and virus titer were examined in BALF of infected mice on days 1-4 p.i. (Fig. 1, 2). Since the amount of BALF from a single mouse was not sufficient for simultaneous multiple cytokine assays, we could not examine the levels of 6 cytokines and a virus titer simultaneously. Therefore, the levels of IL-12, IL-18, IFN- $\gamma$, and virus titer (Fig. 1) and the levels of IL-12, TNF- $\alpha$, and IFN- $\alpha,-\beta$ (Fig. 2) were obtained from two independent experiments using the same infection condition. On day 1 p.i. the virus titer in BALF was 197x higher than the inoculation titer and reached its maximal level on day 3 p.i. (Fig. 1). The body weight of infected mice decreased markedly from day 2 p.i. (data not shown). The productions of IL- 12 , IFN- $\gamma$, and IFN- $\beta$ reached their maximal levels on day 2 p.i. and the maximal production of IL-18, TNF- $\alpha$, and IFN- $\alpha$ was reached on day 3 p.i.. The production of all cytokines examined decreased on day
4 p.i. (Fig. 1, 2). The kinetics of production was similar to the profile of virus titer. However, on day 1 p.i. only IL-12 production was significantly increased as compared with the control and its increase on day 1 p.i. was confirmed in the two separate experiments. However, no significant increase of the other cytokine levels was observed on day 1 p.i. Thus, IL-12 production in the respiratory tract of infected mice preceded the production of IL-18, TNF- $\alpha$, and IFN- $\alpha,-\beta,-\gamma$.

\section{Distribution of cytokines in the lungs of virus-infected mice}

Because IL-12 was characterized as the first cytokine in response to influenza infection in the bronchial epithelium, the production and distribution of IL-12 was analyzed histochemically. Hematoxylin and eosin staining of lungs of influenza virus-infected mice on day 1 p.i. showed that mononuclear cells infiltrated mainly the fibrous connective tissues beneath the bronchiolar smooth muscle coat and partly into the alveolar septi (Fig. 3). Influenza antigen was observed focally in the bronchiolar epithelium and beneath
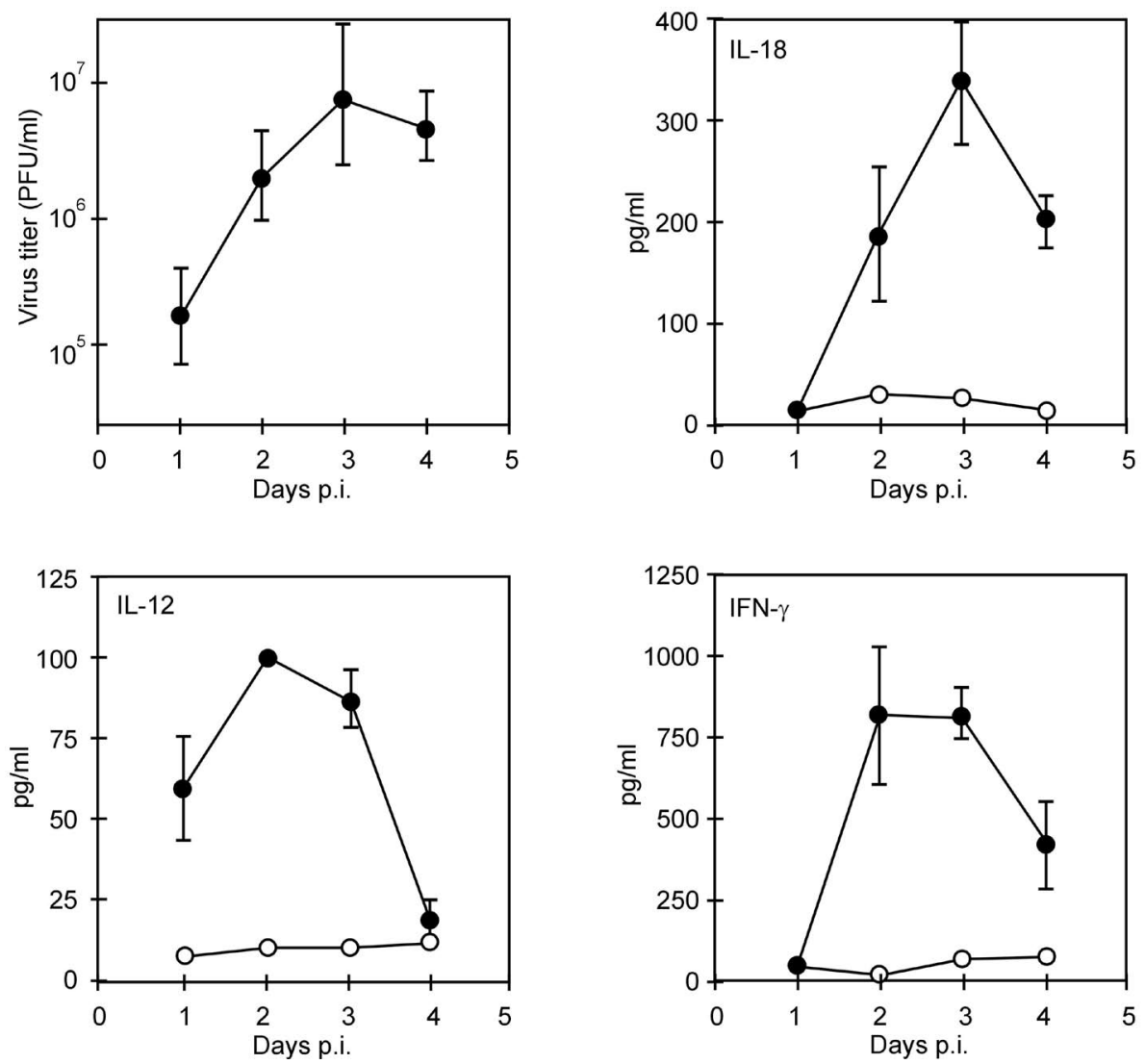

Fig. 1

Kinetics of virus titer and levels of IL-12, IL-18, and IFN- $\gamma$ in BALF from infected (full circles) and mock-infected (empty circles) mice Mean \pm SE values from 4-7 mice. 

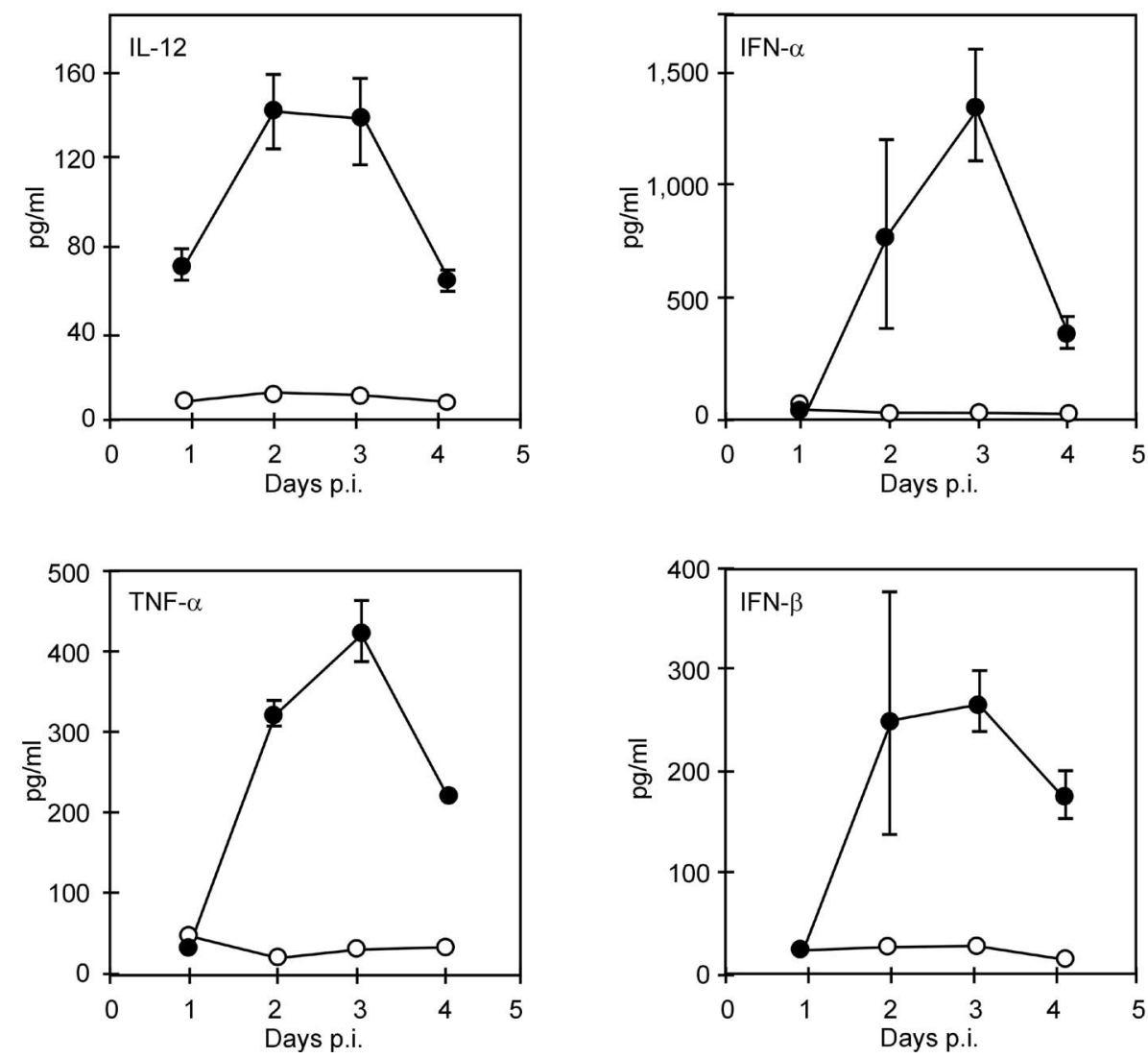

Fig. 2

Kinetics of levels of IL-12, TNF- $\alpha$, IFN- $\alpha$, and IFN- $\beta$ in BALF from infected (full circles) and mock-infected (empty circles) mice Mean \pm SE values from 4-6 mice.

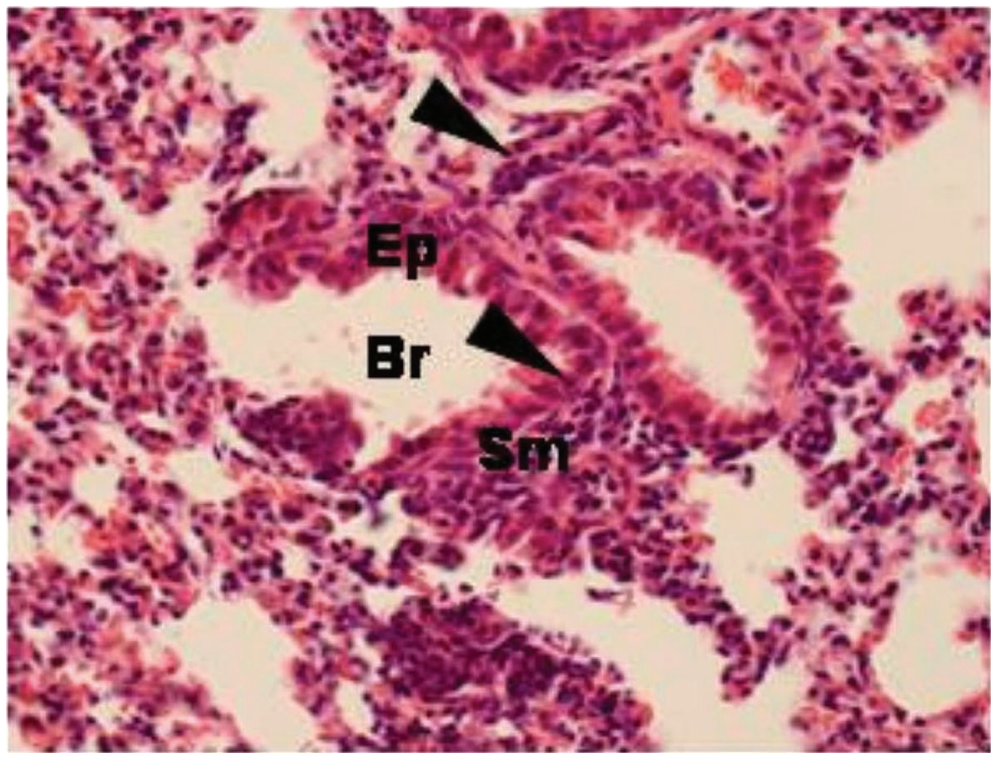

Fig. 3

Histology of the lungs of infected mice on day 1 p.i.

Hematoxylin and eosin staining. Macrophages (arrows), bronchioles (Br), epithelial cells (Ep), smooth muscle cells (Sm). 

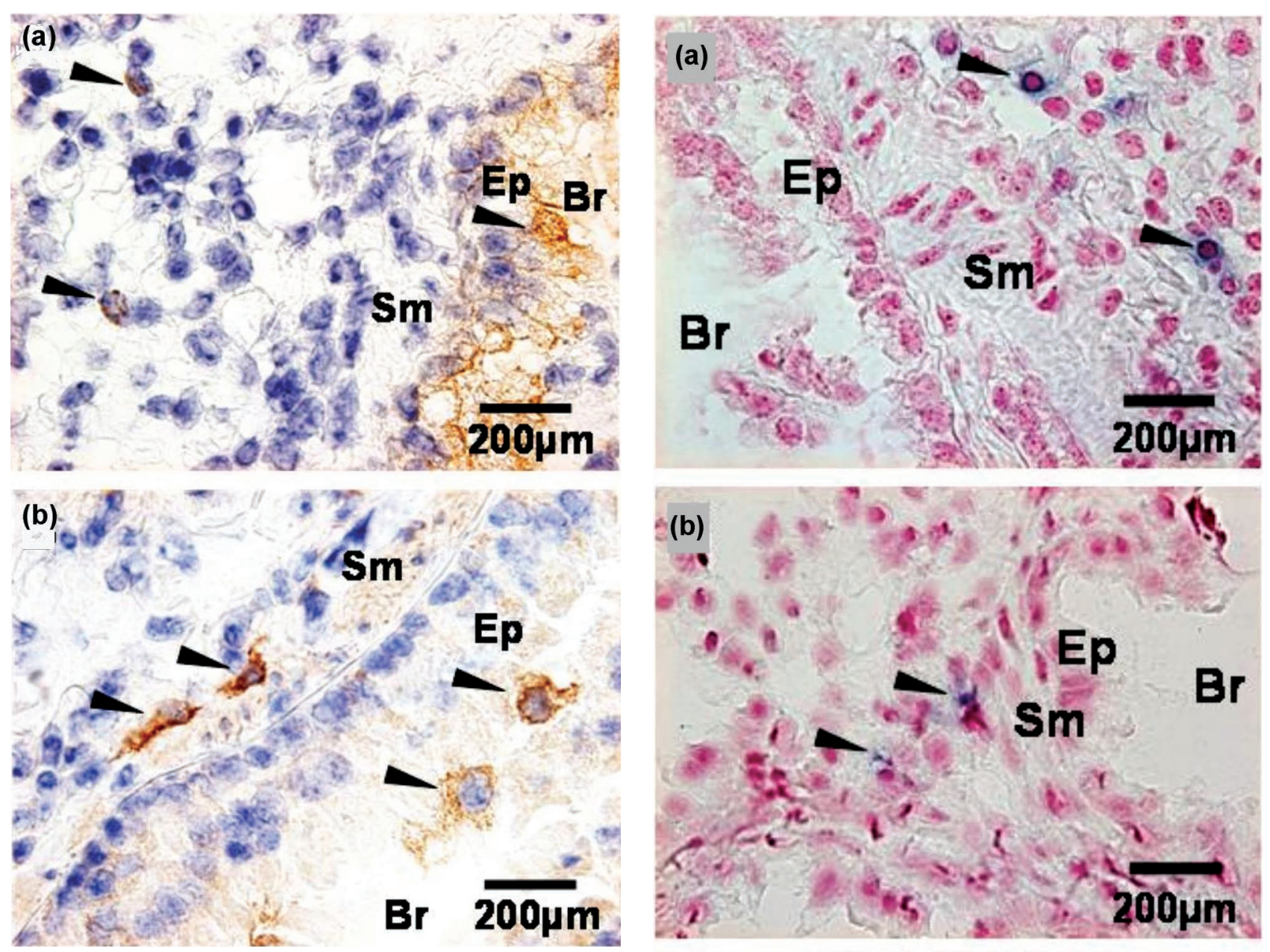

Fig. 4

Localization of viral antigen (a) and macrophages (b) in the lungs of infected mice on day 1 p.i.

Immunohistochemical staining. Viral antigen and macrophages (arrows), bronchioles (Br), epithelial cells (Ep), smooth muscle cells (Sm).

the bronchiolar smooth muscle coat (Fig. 4a). Macrophages were localized beneath the bronchiolar smooth muscle coat and partly in the bronchioles (Fig. 4b). IL-12 staining was observed on the mononuclear infiltrates beneath the smooth muscle coat in the lungs of infected mice (Fig. 5a), but not in the lungs of mock-infected mice (results not shown). We also detected IL-12 mRNA in the sub-epithelial area near the smooth muscle coat (Fig. 5b). IL-12 mRNA was identified on the macrophage-like cells by the absence of staining after RNase treatment (results not shown). IL-12 as well as influenza antigen and macrophages were localized around the smooth muscle coat near the infected epithelial cells. On day 2 p.i., diffuse IL-12 staining was observed in the sub-epi-

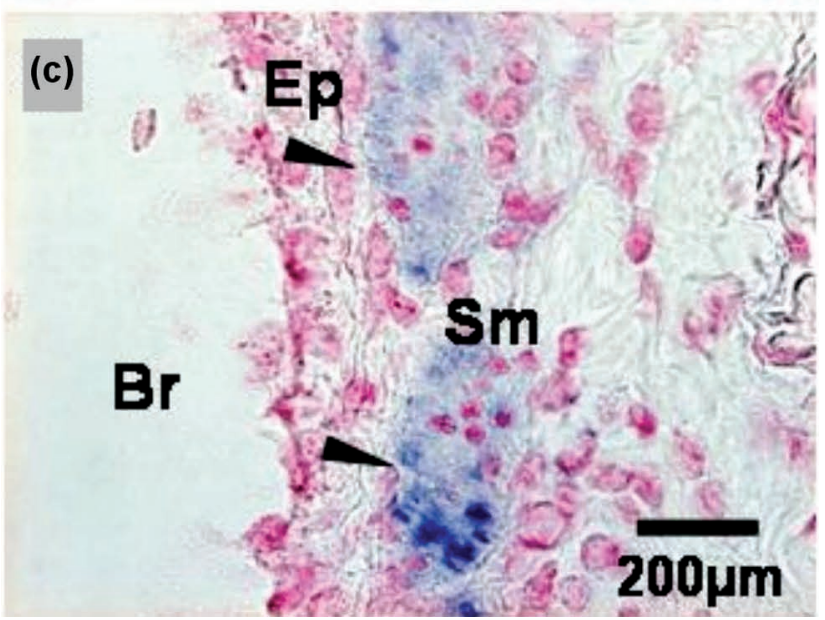

Fig. 5

Localization of IL-12 on days 1 (a) and 2 (c) p.i. and that of IL-12 mRNA on day 1 p.i. (b) in the lungs of infected mice

Immunohistochemical staining. IL-12 (arrows), bronchioles (Br), epithelial cells (Ep), smooth muscle cells (Sm). 
coat (Fig. 5c). No IL-18 or IFN- $\gamma$ staining was detected in the infected lungs on day 1 p.i. (results not shown). On day 2 p.i., IL-18 staining was diffusely observed on the epithelial cells and possibly on desquamated epithelial cells in the infected bronchioles (results not shown). IFN- $\gamma$ staining was observed focally and/or densely in the interstitial area on day 2 p.i. and then on a wide range of pulmonary parenchyma including bronchioles on day 3 p.i. (results not shown). The dominance of IL-12 production in the infected lungs on day 1 p.i. was immunohistochemically confirmed.

\section{Discussion}

In the murine influenza infection model, the production of various kinds of cytokines in the respiratory tract has been shown (Hennet et al., 1992; Kurokawa et al., 1996a,b, 2002; Tsurita et al., 2001; Liu et al., 2004). IL-12, IL-18, TNF- $\alpha$, and IFN- $\alpha,-\beta,-\gamma$ were reported to be produced in the early phase of influenza infection and suggested to direct an early host immunity against the influenza infection (Monteiro et al., 1998; Tsurita et al., 2001; Cheung et al., 2002; Kurokawa et al., 2002; Seo and Webster, 2002; Liu et al., 2004; NeffLaFord et al., 2003; Szretter et al., 2007). We previously showed that augmentation of IL-12 production or intranasal IL-12 administration in the early phase of influenza infection was effective in alleviation of influenza pneumonia in mice (Tsurita et al., 2001; Kurokawa et al., 2002). IL-12 is suggested to be an important immune mediator that contributes to the early host-defense immunity against influenza infection resulting in the alleviation of influenza pneumonia. Thus, in this study we focused on IL-12 production in the airways of influenza virus-infected mice and characterized the mode of $\mathrm{IL}-12$ production in a series of cytokine production in response to the influenza infection.

The production of IL-12 on day 1 p.i. was confirmed in the sub-epithelial area near the bronchiolar smooth muscle coat of lungs. However, the kinetics of cytokine production in the early phase of influenza infection has not been demonstrated clearly. Thus, the finding in this study is probably crucial to understanding the interactions between influenza virus infection and the host immune system including timing and localization of the host defense in influenza infection.

In immunohistochemical analyses, we did not observe IL-18 and IFN- $\gamma$ staining in the infected lungs on day 1 p.i., but did observe the presence of IL-12. Thus, IL-12 production was dominant in the BALF from influenza virus-infected mice on day 1 p.i. In mice, IL-12 contributes to early control of several virus infections including that of Influenza A virus (Monteiro et al., 1998). However, some viruses such as measles virus and Human immunodeficiency virus have been reported to selectively inhibit IL-12 production and induce an immunosuppression (Karp et al., 1996; Braun et al., 2001). The increase of
IL-12 production prior to that of the other cytokines examined in this study suggested that IL-12 played a significant role in priming the cytokine cascade in the influenza infection. In our previous studies, clarithromycin and Kakkon-to, a medicinal herb, augmented IL-12 production on day 2 p.i. in BALF and reduced mortality by alleviating the pneumonia (Tsurita et al., 2001; Kurokawa et al., 2002). Nasal administration of IL-12 on day 2 p.i. only reduced the virus titer in BALF (Tsurita et al., 2001). These results indicated that elevated production of IL-12 on day 2 p.i. might contribute to the reduction of virus titer and alleviation of pneumonia. Thus, elevated IL-12 production before it reached the maximal level observed on day 2 p.i. may be necessary in successful early immunity for the alleviation of influenza symptoms.

Influenza antigen was observed mainly in the bronchiolar epithelium and faintly beneath the bronchiolar smooth muscle coat in the lungs of influenza virus-infected mice on day 1 p.i. By this time, the macrophages were observed beneath the bronchiolar smooth muscle coat and in the bronchioles, and IL-12 staining was observed mostly beneath the bronchiolar smooth muscle coat. We could not exactly verify that macrophages produce IL-12 in the serial sections of the frozen lungs because of weak IL-12 staining, but the distribution of IL-12 staining and macrophages closely overlapped beneath the bronchiolar smooth muscle coat suggesting that macrophages activated by influenza virus antigens produced mainly IL- 12 . While IL- 18 , TNF- $\alpha$, and IFN- $\alpha,-\beta$ are produced not only by macrophages but also by non-immune cells such as epithelial cells, IL-12 is mainly produced by macrophages, monocytes, and dendric cells (D'Andrea et al., 1992; Cameron et al., 1999; Locksley et al., 2001; Pirhonen et al., 2001; Kashiwamura et al., 2002; Pirhonen et al., 2002; Seo and Webster, 2002). Thus, the macrophage may be a key immune cell to induce early defense-immunity against influenza infection and IL-12 is dominantly produced in macrophages activated by influenza virus antigens.

The distribution of IL-12 staining in the sub-epithelial areas on day 2 p.i. was diffuse along the smooth muscle coat of the bronchioles. In comparison to the distribution of IL-12 staining on day 1 p.i., the increased IL-12 production on day 2 p.i. detected in the kinetic analysis was immunohistochemically confirmed. The production of IL-18, TNF- $\alpha$, and IFN- $\alpha,-\beta$, $-\gamma$ also markedly increased in BALF from infected mice on day 2 p.i. Thus, the cooperative and synergistic action of cytokines induced by influenza infection was probably augmented from day 2 p.i. in examined mice model. The present study showed that IL-12 was produced around the infected area of lungs and its production was important in priming of the early immune defense to combat influenza infection.

Acknowledgements. The authors thank Mrs. T. Okuda and A. Hino for technical assistance and Mrs. K. Ono for editorial assistance. This study was partly supported by the grants Nos. 18590129 and 20590131 from the Japan Society for the Promotion of Science. 


\section{References}

Braun MC, Wang JM, Lahey E, Rabin RL, Kelsall BL (2001): Activation of the formyl peptide receptor by the HIVderived peptide T-20 suppresses interleukin-12 p70 production by human monocytes. Blood 97, 3531-3536. doi:10.1182/blood.V97.11.3531

Cameron LA, Taha RA, Tsicopoulos A, Kurimoto M, Olivenstein R, Wallaert B, Minshall EM, Hamid QA (1999): Airway epithelium expresses interleukin-18. Eur. Respir. J. 14, 553-559. doi:10.1034/j.1399-3003.1999.14c12.x

Cheung CY, Poon LL, Lau AS, Luk W, Lau YL, Shortridge KF, Gordon S, Guan Y, Peiris JS (2002): Induction of proinflammatory cytokines in human macrophages by influenza A (H5N1) viruses: a mechanism for the unusual severity of human disease? Lancet 360, 1831-1837. doi:10.1016/S0140-6736(02)11772-7

D`Andrea A, Rengaraju M, Valiante NM, Chehimi J, Kubin M, Aste M, Chan SH, Kobayashi M, Young D, Nickbarg E (1992): Production of natural killer cell stimulatory factor (interleukin 12) by peripheral blood mononuclear cells. J. Exp. Med. 176, 1387-1398. doi:10.1084/jem.176.5.1387

Fukuda Y, Yamamura J, Uwano T, Nishijo H, Kurokawa M, Fukuda M, Ono T, Shiraki K (2003): Regulated transgene delivery by ganciclovir in the brain without physiological alterations by a live attenuated herpes simplex virus vector. Neurosci. Res. 45, 233-241. doi:10.1016/S01680102(02)00235-3

Furuta Y, Takahashi K, Fukuda Y, Kuno M, Kamiyama T, Kozaki K, Nomura N, Egawa H, Minami S, Watanabe Y, Narita $\mathrm{H}$, Shiraki K (2002): In vitro and in vivo activities of anti-influenza viral compound T-705. Antimicrob. Agents Chemother. 46, 977-981. doi:10.1128/AAC.46.4.977981.2002

Hayden FG, Fritz RS, Lobo MC, Alvord WG, Strober W, Straus S (1998): Local and systemic cytokine responses during experimental human influenza A virus infection: relation to symptom formation and host defense. J. Clin. Invest. 101, 643-649. doi:10.1172/JCI1355

Hennet T, Ziltener HJ, Frei K, Peterhans E (1992): A kinetic study of immune mediators in the lungs of mice infected with influenza A virus. J. Immunol. 149, 932-939.

Imakita M, Shiraki K, Yutani C, Ishibashi-Ueda H (2000): Pneumonia caused by rhinovirus. Clin. Infect. Dis. 30, 611-612. doi: $10.1086 / 313723$

Kaiser L, Fritz RS, Straus SE, Gubareva L, Havden FG (2001): Symptom pathogenesis during acute influenza: interleukin-6 and other cytokine responses. J. Med. Virol. 64, 262-268. doi:10.1002/jmv.1045

Kamiyama H, Kurimoto M, Yamamura J, Uwano T, Hirashima Y, Kurokawa M, Endo S, Shiraki K (2001): Effect of immunity on gene delivery into anterior horn motor neurons by live attenuated herpes simplex virus vector. Gene Therapy 8, 1180-1187. doi:10.1038/sj.gt.3301503

Karp CL, Wysocka M, Wahl LM, Ahearn JM, Cuomo PJ, Sherry B, Trinchieri G, Griffin DE (1996): Mechanism of suppression of cell-mediated immunity by measles virus. Science 273, 228-231. doi:10.1126/science.273.5272.228
Kashiwamura S, Ueda H, Okamura H (2002): Roles of interleukin18 in tissue destruction and compensatory reactions. J. Immunother. 25, S4-11. doi:10.1097/00002371200203001-00002

Kurokawa M, Brown J, Kagawa Y, Shiraki K (2003): Cytokineregulatory activity and therapeutic efficacy of cynnamyl derivatives in endotoxin shock. Eur. J. Pharm. 474, 283-293. doi:10.1016/S0014-2999(03)02036-3

Kurokawa M, Imakita M, Kumeda C., Shiraki K (1996a): Cascade of fever production in mice infected with influenza virus. J. Med. Virol. 50, 152-158. doi:10.1002/(SICI)10969071(199610)50:2<152::AID-JMV8>3.0.CO;2-9

Kurokawa M, Imakita M, Kumeda CA, Yukawa TA, Shiraki K (1996b): Kakkon-to suppressed interleukin-1 production responsive to interferon and alleviated influenza infection in mice. J. Tradit. Med. 13, 201-209.

Kurokawa M, Kumeda CA, Yamamura J, Kamiyama J, Shiraki K (1998): Antipyretic activity of cinnamyl and related compounds in Kakkon-to, a traditional medicine, in influenza virus-infected mice. Eur. J. Pharmacol. 348, 45-51. doi:10.1016/S0014-2999(98)00121-6

Kurokawa M, Tsurita M, Brown J, Fukuda Y, Shiraki K (2002): Effect of interleukin-12 level augmented by Kakkon-to, a herbal medicine, in the early stage of influenza infection on its alleviation. Antiviral Res. 56, 183-188. doi:10.1016/ S0166-3542(02)00104-3

Liu B, Mori I, Ossain HMJ, Dong L, Takeda K, Kimura Y (2004): Interleukin-18 improves the early defense system against influenza virus infection by augmenting natural killer cell-mediated cytotoxicity. J. Gen. Virol. 85, 423-428. doi:10.1099/vir.0.19596-0

Locksley RM, Killeen N, Lenardo MJ (2001): The TNF and TNF receptor superfamilies: integrating mammalian biology. Cell 104, 487-501. doi:10.1016/S0092-8674(01)00237-9

Monteiro JM, Harvey C, Trinchieri G (1998): Role of interleukin12 primary influenza virus infection. J. Virol. 72, 4825-4831.

Neff-LaFord HD, Vorderstrasse BA, Lawrence BP, Fewer BP (2003): CTL, not enhanced NK cells, are sufficient for viral clearance from the lungs of immunocompromised mice. Cell Immunol. 226, 54-64. doi:10.1016/ j.cellimm.2003.11.005

Pirhonen J, Matikainen S, Julkunen I (2002): Regulation of virusinduced IL-12 and IL-23 expression in human macrophages. J. Immunol. 169, 5673-5678.

Pirhonen J, Sareneva T, Julkunen I, Matikainen S (2001): Virus infection induces proteolytic processing of IL-18 in human macrophages via caspase- 1 and caspase- 3 activation. Eur. J. Immunol. 31, 726-730. doi:10.1002/15214141(200103)31:3<726::AID-IMMU726>3.0.CO;2-5

Seo SH, Hoffmann E, Webster RG (2002): Lethal H5N1influenza viruses escape host anti-viral cytokine responses. Nature Med. 8, 950-954. doi:10.1038/nm757

Seo SH, Webster RG (2002): Tumor necrosis factor alpha exerts powerful anti-influenza virus effects in lung epithelial cells. J. Virol. 76, 1071-1076.

Szretter KJ, Gangappa S, Lu X, Smith C, Shieh W-J, Zaki S, Sambhara S, Tumpey TM, Katz JM (2007): Role of host 
cytokine responses in the pathogenesis of avian $\mathrm{H} 5 \mathrm{~N} 1$ influenza viruses in mice. J. Virol. 81, 2736-2744. doi:10.1128/JVI.02336-06

Tsurita M, Kurokawa M, Imakita M, Fukuda Y, Watanabe Y, Shiraki K (2001): Alleviation of influenza infection by early augmentation of interleukin (IL)-12 level in the airway of mice administered orally with clarithromycin or intranasally with IL-12. J. Pharmacol. Exp. Therapeut. 298 362-368.

Van Reeth K (2000): Cytokines in the pathogenesis of influenza. Vet. Microbiol. 74, 109-116. doi:10.1016/S03781135(00)00171-1 